\title{
Exploration and Research on the Training Path of Cybersecurity Application-oriented Talents by the Integration of Industry and Education
}

\author{
Zhanxiang Ye, Shihua Liu*, Hao Zhang, Gang Wu \\ Department of Information Technology, Wenzhou Polytechnic, Wenzhou, China
}

Email address:

wzynetwork@wzvtc.edu.cn (Shihua Liu)

${ }^{*}$ Corresponding author

\section{To cite this article:}

Zhanxiang Ye, Shihua Liu, Hao Zhang, Gang Wu. Exploration and Research on the Training Path of Cybersecurity Application-oriented Talents by the Integration of Industry and Education. Education Journal. Vol. 9, No. 5, 2020, pp. 137-141. doi: 10.11648/j.edu.20200905.13

Received: August 22, 2020; Accepted: September 10, 2020; Published: September 21, 2020

\begin{abstract}
In recent years, with the advancement of information and intelligence, the importance of network and information security is increasingly prominent, and it has been the focus of the government, education institutions and society on how to cultivate applied cybersecurity talents. However, due to the lack of practical application scenarios and effective practical teaching methods, the cultivation of network and information security talents in school does not match the social demand for applied talents. By setting up "Cybersecurity Technology Service Center", Wenzhou Polytechnic has built a cybersecurity talent cultivation ecosystem of college, government and enterprises with complementary advantages, demand docking and win-win cooperation, creating an environment for training applied network and information security talents. This paper explores the operation mode of the simultaneous development of technical services and talent training, assist customized talents training with localized technical services, and guarantee localized technical services with customized talents training, so as to promote professional skills flow from enterprises to schools and skilled talents flow from schools to enterprises in a two-way cycle. As a result, we should deepen the integration of industry and education, cultivate talents with dual cooperation, continuously optimize the ecology of talent training, and cultivate application-oriented cybersecurity talents with vocational education characteristics, who are in line with the post standards of enterprises.
\end{abstract}

Keywords: Application-oriented Talents, Ecosystem, Integration of Industry and Education, Collaborative Education

\section{Introduction}

As early as in 2010, The United States started "The National Initiative for Cybersecurity Education (NICE)", with The country's overall layout and action, to strengthen systematize and normalize work for national cybersecurity awareness, formal cybersecurity education, cybersecurity workforce training and professional development. NIST, as the interagency lead for NICE, officially released "NICE Cybersecurity Workforce Framework" in 2017 [1].

Office of the Central Cyberspace Affairs Commission, China's cybersecurity authority, issued the "Opinions on Strengthening Discipline Construction and Personnel Training of Cybersecurity" in 2016. It is proposed to improve the cybersecurity personnel training system for junior college, undergraduate, postgraduate education and on-the-job training, Innovate cybersecurity personnel training mechanism, Strengthen the construction of cybersecurity teaching materials and teaching staff, promote cooperation between institutions of higher learning and industrial enterprises.

\section{Practice of Cybersecurity Talent Cultivation}

In 2001, Wuhan University was the first to set up an undergraduate major in network and information security 
in China, and It has been 20 years for the training of network and information security talents in universities. However, for a long time, due to the particularity of the network and information security industry, the cybersecurity personnel training in school has no practical application scene and effective practical teaching means. It leads to the mismatch between the training of cybersecurity personnel in universities and the demand of applied talents in society.

Since 2012, Wenzhou Polytechnic has carried out practice and exploration of cybersecurity application-oriented personnel training. There is no mature mode for vocational education to develop cybersecurity talents training. In order to obtain the professional ability and teaching resources needed for the training of cybersecurity application talents, Wenzhou Polytechnic set up "Cybersecurity Technical Service Center (CTSC)" to carry out localized cybersecurity technical services and promote application-oriented cybersecurity personnel training with technical services. It has successively carried out the practice and exploration of various talent cultivation methods, such as certification training of junior testing and evaluation engineer for classified protection of cybersecurity, apprenticeship training of cybersecurity operation and maintenance engineer, customized training of cybersecurity engineer for blue team, and achieved certain results [2].

\section{Exploration of Talents Cultivation Path of Industry and Education Integration}

In 2017, the General Office of the State Council of issued "several Opinions on Deepening the Fusion of Industry and Education", which clearly put forward the guiding ideology of promoting the all-round integration of elements on the supply side and demand side for talent training, and cultivating technical and skilled talents [3].

Wenzhou Polytechnic has been adhering to the practice and exploration of the combination of industry, education and research to train application-oriented cybersecurity personnel. Similar to many regions, there is no professional cybersecurity firms in wenzhou, local cybersecurity services rely on nonlocal network and information security companys. According to situation of cybersecurity industry in Wenzhou, Wenzhou Polytechnic established CTSC. Under the guidance of the government's cybersecurity authorities, school and enterprises cooperate to carry out localized cybersecurity services. It guides the industry to participate in education, Jointly cultivates cybersecurity personnel, and promotes the comprehensive reform and construction of the integration of industry and education, including the key elements of talent training, such as faculty team, infrastructure and operation mechanism [4]. The training path of integration of industry and education is shown in Figure 1.

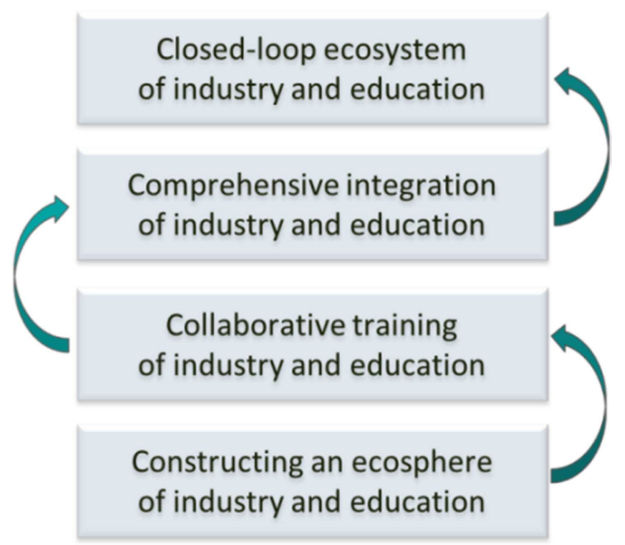

Figure 1. Training path of integration of industry and education.

\subsection{Constructing an Ecosphere of Industry and Education}

Different from other IT industries, cybersecurity has a very strict management mechanism and technical specification requirements. Only with the support of competent government departments and in-depth cooperation with Professional manufacturers, can we develop technical services and application-oriented personnel training in cybersecurity.

Government departments in charge are the supervisors of cybersecurity. They hope to cultivate localized cybersecurity technical forces and provide technical support for their work. As the provider of cybersecurity products and technical services, cybersecurity manufacturers need localized front-end technical personnel for cybersecurity operation and maintenance and emergency response, so as to improve the response ability and reduce the operation cost. A large number of local enterprises and institutions are the demand sides of cybersecurity technical services and personnel training, in need of a large number of cybersecurity silled talents. Localized technical services and customized personnel training can well meet the needs of all parties in the cybersecurity industry chain.

Based on win-win cooperation, Wenzhou Polytechnic has established an industry and education alliance with Wenzhou Network and Information Security Notification Center, DBAPPSecurity Information Technology Co., LTD., Hangzhou Anxin Cybersecurity Testing Technology Co., LTD., And Qi-Anxin Technology Group Co., LTD. Under the guidance of government authorities, school and enterprises shall cooperate to carry out localized technical services and customized personnel training, and constructe a cybersecurity personnel training ecosystem featuring complementary advantages, demand docking and win-win cooperation. It promotes the integration of industry and education $[5,6]$.

\subsection{Collaborative Cultivation of Industry and Education}

Based on CTSC, We provide both technical services and personnel training, to promote customized personnel training with localized technical services, and to guarantee localized technical services with customized personnel training. This will meet the common interests of all parties in the industry chain, and promote the in-depth participation of enterprises 
and competent government departments in talents training.

Wenzhou Polytechnic and DBAPPSecurity Information Technology Co., LTD. jointly built "Wenzhou technical service center of DBAPPSecurity", to carry out collaborative cultivation of "cybersecurity operation and maintenance engineers" and "cybersecurity emergency response engineers" in the apprenticeship mode. We work together to formulate the talent training scheme oriented to employment, develop a curriculum system with post skills as the core, promote customized talent training docking post standard. The cooperative enterprise gives full play to its own advantage of industry background, is responsible for the project teaching, competition guidance, productive practice and other practical teaching, and provides high-quality jobs for customized talents [7].

As the technical support unit of the competent government departments, The teachers and students of the institute actively participate in the cybersecurity works of the government, such as G20 conference cybersecurity protection in Wenzhou, and assist government departments to carry out the cybersecurity employee training, the cybersecurity awareness education, cybersecurity skills competition, etc. Otherwise, we regularly invite officials from cybersecurity regulatory authorities to strengthen the cybersecurity legal awareness education for students.

\subsection{Comprehensive Integration of Industry and Education}

Relying on CTSC, technical services and personnel training should be carried out simultaneously to break through the original barriers between industry and education. Industry and education should be transformed from division to integration, and the reform of the key elements of talent cultivation, such as teaching team, teaching facilities, teaching resources, teaching methods and operation mechanism, etc., should be promoted [8].

The school and the cooperative enterprises jointly formulate customized talent training programs [9]. In order to meet the industry professional standards and enterprise posts requirements, we should cultivate application-oriented skilled talents, such as cybersecurity inspection, cybersecurity operation and maintenance, cybersecurity emergency response and other technical posts. The precise orientation of talent training is in line with the characteristics of application-oriented talent training in vocational education, and also differentiated competition with undergraduate education. We should build a customized curriculum system integrating professional skills required by enterprise post into professional courses, strengthen practical teaching, and form systematic practical training system such as professional course experiment, simulation comprehensive training, CTF competition, project teaching and post practice [10,11].

We jointly build the practical training base for the integration of production, learning and research. Guided by network security technical services and combined with the practical teaching requirements of customized talent training, we have built the productive practical training infrastructure, such as offensive and defensive training platform, situational awareness system, website security monitoring system, Information system security detection toolbox and so on. In addition to meeting the needs of practical teaching and social training, the base also carries out technical research and development and technical services. It has been awarded "Wenzhou Cybersecurity Personnel Training Base" by the government, and we are now applying for "Wenzhou Cybersecurity Engineering Research Centre" [12].

Multiple approaches should be taken simultaneously to build a double-qualified teaching team. In the long-term practice, we have been exploring the construction mechanism of school-enterprise mutually beneficial double-qualified teaching team. A long-term mechanism of "one platform and three measures" has been formed. We have set up CTSC in the school to provide a supporting platform for the cultivation of double-qualified teachers through the simultaneous development of technical services and talents training. Due to the localization of technical services in school-enterprise cooperation, teachers participate in technical training of cooperative enterprises and take temporary posts in corresponding departments of cooperative enterprises to improve their technical and practical ability. The cooperative enterprise establishes a teaching team and bring in senior engineers to run apprenticeships and customised vocational training courses. We support teachers to obtain national cybersecurity professional qualification certification, such as CISP, CISP-PTE, CISP-IRE, and CISP-F, etc., and take part in technical service and social training projects sponsored by cooperative enterprises and government authorities [13].

\section{Innovation in the Training Mode of Application-oriented Talents}

It has become a basic state policy of China to vigorously develop vocational education and train high-quality skilled personnel. Based on the characteristics of vocational education, Wenzhou Polytechnic actively explores the talent training path of integrating of industry and education, and gradually forms the application-oriented talent training mechanism of "simultaneous development of technical service and talent cultivation, and two-way circulation of skills flow and talents flow", as illustrated in Figure 2.

\subsection{Building the Integrated Ecosystem of Industry and Education by the Simultaneous Development of technical Services and Talent Training}

At present, the school-enterprise cooperation system in China is not mature, and the supporting policies are still being improved. In this context, the school led the initiative, combined with industry stakeholders to build a talent cultivation ecosystem of integration of industry and education. Relying on CTSC, we develop both localized technical service and customized talent training, promote customized talent training with localized technical service, and guarantee localized technical service with customized talent training. We will create an ecosystem of talent cultivation for schools, 
governments and enterprises with resource sharing, complementary advantages and demand docking, break through the existing barriers of talent cultivation and technical services in industry and education, and carry forward the all-round integration of structural elements on the supply side and the need side of talent cultivation [14].

\subsection{Creating a Closed Loop of talent Training with the Two-Way Cycle of Technology Flow and Talent Flow}

For a long time, the talent cultivation in colleges and universities is only a one-way process from school to enterprise, and it is difficult to make in-depth breakthroughs in school-enterprise cooperation in training applied talents.
Relying on CTSC, we develop both personnel training and technical services. Local technical services are used to promote the flow of professional skills from enterprises to schools, and customized talents training is used to facilitate the flow of skilled personnels from schools to enterprises in a two-way cycle. Thus, a PDCA closed loop of talent training has been constructed, which is "customized talent training scheme (Plan) $\rightarrow$ collaborative training by industry-education integration (Do) $\rightarrow$ post practice and optimum post employment (Check) $\rightarrow$ revision and improvement of talent training scheme (Action)". And it continues to optimize talent cultivation positioning, talent cultivation standards, talent cultivation contents and talent cultivation methods [15].

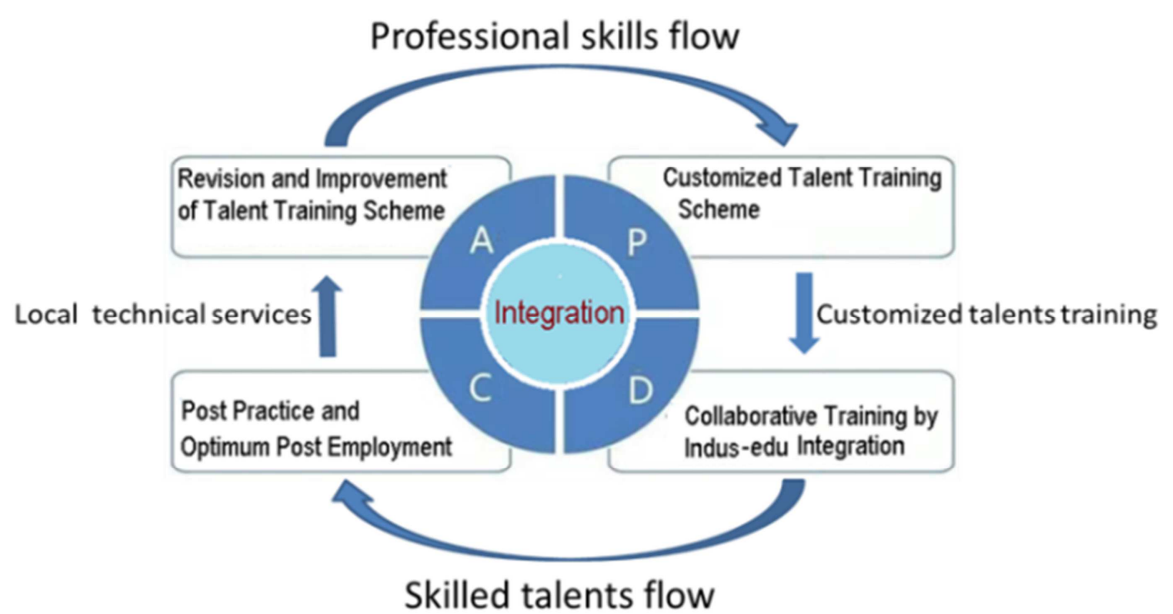

Figure 2. Closed-loop ecosystem of application-oriented talents training.

\section{Effectiveness of Cybersecurity Talents Training}

It has achieved significant results In the training of cybersecurity applied talents by deepening the integration of industry and education.

In recent years, the students take part in all kinds of high level competition, won the first prize in provincial college students' cybersecurity competition for many times, and obtain good record in major industrial events, such as "QiangWang Cup" National Cybersecurity Challenge, "SimpleEdu Cup" Information Security Triathlon, and "DBAPPSecurity Cup" College Students' Cybersecurity Competition.

The employment quality of students has gradually improved. More and more graduates have been recruited into well-known information security companies and institutions, such as DBAPPSecurity and Qi-Anxin.

At the same time, all of our in-depth cooperation enterprises have been awarded as industry-education integrated enterprises by the government, and have made great progress during the cooperation period. For example, DBAPPSecurity Information Technology Co., LTD. has also grown from a regional enterprise in Zhejiang province at the beginning of the cooperation into a global top 500 cybersecurity enterprise with nearly 2800 employees, and successfully listed on SSE STAR MARKET.

\section{Conclusion}

Starting from the analysis of the role of industry education integration in the cultivation of applied talents, this paper summarizes the path to realize the integration of industry and education by combining talent training with technical services, and expounds the cybersecurity applied talent training mode adopted by the information security and management major of Wenzhou Polytechnic.

The key to realizing application-oriented cybersecurity talents training lies in the reconstruction of talents training mode based on the integration of industry and education, including training program, teaching resources, teaching team, training base and operation mechanism, etc. Through the mutual promotion of localized technical services and customized talent training, two-way flow of professional skills qualified talents can break through the gap between industry and education to achieve real integration.

\section{Acknowledgements}

This paper is supported by the following fund projects, in no particular order:

1. The first batch of teaching reform research Projects in the 13th Five-Year Plan of Higher Education in Zhejiang Province, the Technical service Center jointly built by 
government, enterprise and college, and the construction of an ecological circle for the integration of industry and education, taking the application-oriented personnel training of higher vocational Cybersecurity as an example (No. jg20180583)

2. Major Teaching Reform Project of Wenzhou Polytechnic: "The exploration of the "Wenzhou Polytechnic mode" for the Gamification cultivation of practical network security talents cooperate with Government and enterprise cooperation" ( No. WZYZD201807)

3. Cooperation Project of School-Enterprise and Enterprise for Visiting Engineers of Higher School in Zhejiang Province: "Research on the Training Mode of Network Security Actual Personnel in Higher Vocational School-Enterprise Cooperation of Project Training Level "(No. FG2018064)

4. Major Teaching Reform Project of Wenzhou Polytechnic: The construction and research of the cyber space security training platform based on the integration of industry and education from the perspective of "Internet +" (No. WZYZD201806).

\section{References}

[1] Shoemaker D, Kohnke A, Sigler K. A Guide to the National Initiative for Cybersecurity Education (NICE) Cybersecurity Workforce Framework (2.0) [M]. Auerbach Publications, 2016.

[2] Jian Gao. Exploration on the Construction of Network Security Experimental Class in Police Colleges [J]. Computer Education, 2019 (5): 97-100.

[3] Jing Zhou, Jinfeng Yue. Report on Deepening Industry-Education Integration of School-Enterprise Cooperation in Modern Vocational Education with Chinese Characteristics since the 18th National Congress of the CPC [J]. Vocational and Technical Education, 2017, 38 (024): 45-52.

[4] Jingchao Ai. Construction of an Application-oriented Talent Training Model integrating Industry and Education in Local Universities [J]. Education Forum, 2020 (32): 128-130.
[5] Xiaojing Xu. Construction of "Industry Education Integration" Ecosystem in Higher Vocational Colleges [J]. Education and Vocation, 2018, No. 916 (12): 53-56.

[6] Yufen Li. Construction of Industry Education Integration Ecosystem of Vocational Education in the New Era [J]. Education and Vocation, 2018, 000 (020): 19-25.

[7] Siyao Yu. Practice and Exploration of School Enterprise Collaborative Education Mode in Higher Vocational Colleges -- Taking Talent Training of Order Class as an Example [J]. Vocational \& Technical Education Forum, 2018, 000 (006): 138-141, 147.

[8] Zhijie Chen. Connotation, Essence and Practice Path of the Integration of Industry and Education in Vocational Education [J]. Education and Vocation, 2018, 000 (005): 35-41.

[9] Mengqing Li, Xiao Xing. Research on the Reconstruction of Talent Training Program of Higher Vocational Education under the Background of "Double High Program" [J]. Modern Education Management, 2020 (1): 107-114.

[10] Xiaosong Zhao. "Network Security" Course Teaching Innovation [J]. Journal of Tianjin Vocational Institutes, 2019 (7): $37-40$.

[11] Song Wei. Research on the Systematic Training of Network Security Competition in Higher Vocational Colleges [J]. Journal of Fujian Computer, 2020 (3): 50-51.

[12] Xiyu Tang. Research and Practice on the Construction of Productive Training Base of School Enterprise Cooperation in Higher Vocational Education [J]. Vocational \& Technical Education Forum, 2018, 000 (004): 121-125.

[13] Zhixiang Gu. Research on the Construction Path of "Double Qualification" Teachers Team in Higher Vocational Colleges under the Background of Industry Education Integration [J]. Vocational \& Technical Education Forum, 2019, 000 (002): 99-102.

[14] Linfeng Hu, Genhou Liu. Construction of Industry Education Integration Mechanism from the Perspective of Ecology [J]. Education and Vocation, 2018, 000 (003): 18-23.

[15] Hu Lei, Rui Dong, Chenglong Li. Application of "PDCA" Circulation Management Method in Talents Cultivation of Industry Education Integration [J]. Education Review, 2015, No. 197 (11): 71-74. 